\title{
MONITORING AND CONTROL PARAMETERS OF GAS PIPELINE BY USING PLC AND SCADA SYSTEM
}

\author{
Rahul S. Joshi, Pritesh P. Patil, Rushikesh N. Dalavi, Abhilash C. Patil, \\ Department of Electrical Engineering Vishwaniketan Institute of \\ Management and Engineering Technology. \\ Mumbai- 410202, India \\ Prof. Sarthak K. Joshi \\ (Assistant Professor) \\ Department of Electrical Engineering Vishwaniketan Institute of \\ Management and Engineering Technology. \\ Mumbai- 410202, India
}

\begin{abstract}
This paper presents the system which monitors and controls the various parameter of gas pipeline (temperature, pressure and flow) using PLC \& SCADA system. This is industrial automation project hence we are using PLC and SCADA system which is the most popular and easy to use control system in industrial applications. PLC is the brain of our project, all components are connected to the PLC and SCADA software is used to give command to the PLC and to visualize all the process. PLC gathers all information from sensors connected to it (temperature sensor - RTD, flow sensor and pressure transducer). After that all the data collected from sensors is bring together and signified in the SCADA system in different layout. SCADA (Supervisory Control And Data Acquisition) system is the most powerful software for real time monitoring equipment and processing the data.

Another topic which is included in this paper is leak detection, leakage in pipeline network is also one of the foremost causes of limitless losses in network of gas pipeline. Due to enormous rate of failure of pipeline, it results into human influences, environmental disasters and economic loss. To avoid such hazardous situation and maintain reliable, safe, and un-interrupting pipeline infrastructure, this system is developed for leakage detection in pipeline system.
\end{abstract}

Keywords- Gas Automation, leakage detection, PLC \& SCADA system, PNG, PID controller.

\section{INTRODUCTION}

Natural gas is one of the world's leading energy sources. Nevertheless, gas consuming areas are typically far away from the gas storage and development areas. Because of this, transporting and supplying the gas from storage station to different market areas is very difficult. It is also very important that the parameters of the gas pipeline such as temperature, pressure, flow, compressor status etc. are constantly monitored and managed. The gas pipeline, PLC and SCADA system are used for comprehensive and safe monitoring.

In the automatic gas pipeline control system, PLC and SCADA monitor the parameters of the transport of gas pipelines using all types of equipment and instruments. This is used for field equipment control and modification. The primary goal is to supply the customer with the gas in the safest and most cost-effective way possible. Furthermore, the automation system can also reduce the amount of work required, improve the environmental level and save costs.

PNG has a significant market in the current scenario as Piped Natural Gas. For home cooking and heating purposes, etc. PNG is used. PNG meets most of the fuel requirements in all segments, which are efficient, non-polluting and relatively economical.

\section{LITERATURE SURVEY}

Different monitoring and control systems for gas pipeline automation and various methods of leak detection are conducted for the literature survey. There is a huge estimated economic loss from pipeline failure. There are large-scale property losses in the USA as a result of pipeline collisions, costing almost $\$ 7$ billion, killing over 500 people and injuring over 1000. Something similar occurred on 6 September 2010 in California, USA, in another pipeline collapse accident, in which eight people were killed and over 50 wounded.

The causes of pipeline damage are not immediate, since various conditions fluctuate. Fig. 1 shows a pie charts which show the principal causes of pipeline failure, including human 


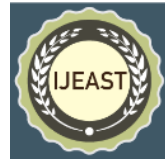

error, construction defects, pipeline corrosion, and faults during external factors and production processes.

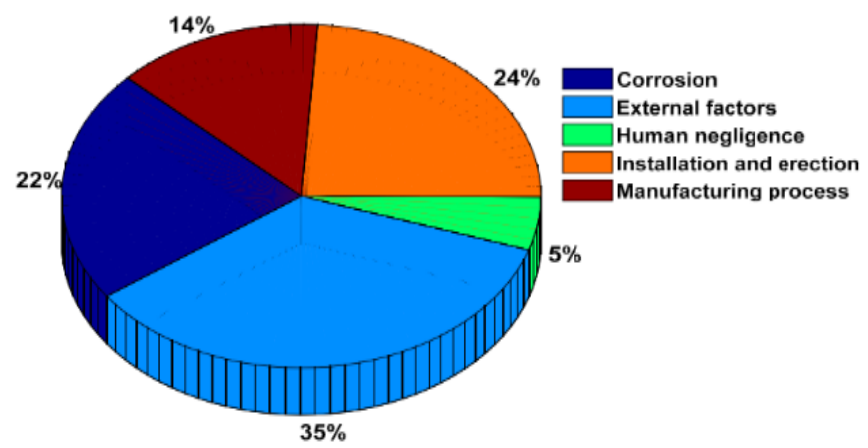

Fig.1 Pie chart showing statistics of the sources of pipeline failure

According to this data, pipeline leakage events are not so easy to prevent permanently as the causes of the failures differ. However, it is important to track pipelines for leakage detection in time to reduce the impacts of petroleum and gas leakage on society. Injuries, damages and other serious social and environmental consequences related to pipeline failure may therefore be minimized.

\section{PNG Properties:}

\begin{tabular}{|c|c|}
\hline Physical state & Gas \\
\hline Colour & Colourless \\
\hline Odour & $\begin{array}{l}\text { Odourless (Ethyl Mercaptan is } \\
\text { added as odorant for easy detection } \\
\text { through smell.) }\end{array}$ \\
\hline Boiling point & $161.5^{\circ} \mathrm{C}$ \\
\hline Melting point & $182^{\circ} \mathrm{C}$ \\
\hline Vapour density & 0.6 to 0.7 (w.r.t air) \\
\hline Flammability ratio & 5 to $15 \%$ by volume in air \\
\hline Auto ignition temp. & $540^{\circ} \mathrm{C}$ \\
\hline
\end{tabular}

\section{Growth of PNG:}

Taking into account the security factors and advantages of PNG, PNG now has enormous demand and is rising worldwide, including India. PNG saves more than other conventional fuels economically. PNG is also much safer than other fuels because it is lighter than air and avoids spontaneous inflammation. The PNG installation project will be completed in Mumbai and surrounding suburbs, as well as in some regions within 2 to 3 years.

\section{SOFTWARE REQUIRMENT}

- $\quad$ PLC Software : RS LOGIX 500

- Communication software : RS LINX CLASSIC

- SCADA Software : FACTORY TALKVIEW

\section{HARDWARE REQUIRMENT}

- $\quad$ PLC used : ALLEN BRADLY 1400 (series A)

- Solenoid valves, compressor, temperature sensor, flow sensor, pressure transducer, push buttons, etc.

\section{BLOCK DIAGRAM}

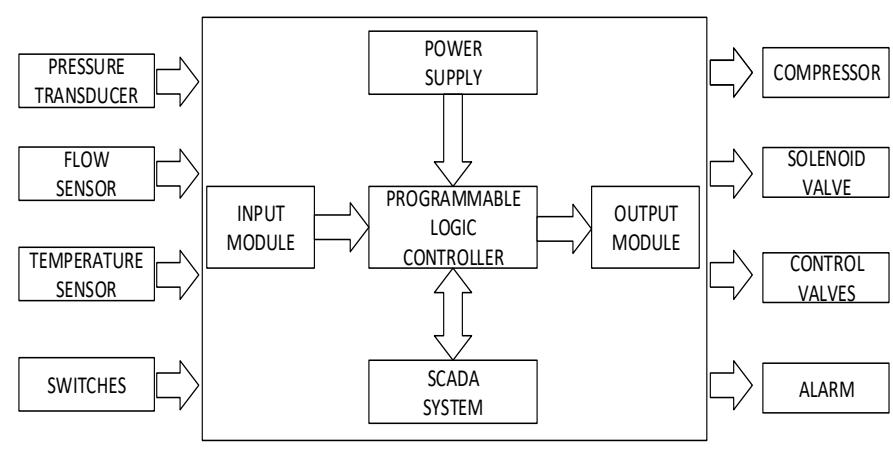

Fig. 2 Block Diagram

A. Programmable Logic Controller (PLC):

PLC is the abbreviation of Programmable logic controller. Now a days PLC's are useful in the number of industries for automation purposes. PLC's are basically used to control automated systems in industrial application. They are developed as well as simplest form of control system which are now substitute for HardWired Logic Relays at a large scale.

B. Supervisory Control And Data Acquisition (SCADA):

SCADA is termed as Supervisory Control and Data Acquisition. To control equipment and to process the data, we can use the SCADA system as it is the most dominant program. The inputs provide the SCADA system with information after processing and displaying data and act on it. SCADA plays a significant role in industrial organisations, as it relates to the interaction between hardware and software. SCADA thus enables the operator to properly control the processes and the equipment (controllers, equipment for communication and I / O devices).

SCADA systems consists of various subsystems, from which programmable logic controllers (PLCs) and the remote terminal units (RTUs) are the most important one.

C. Pressure transducer:

Pressure transducer or pressure transmitter, it helps to convert pressure signal into an analog electrical signal. Pressure transducer measures pressure (liquid pressure or air pressure). They inform operator about the pressure 


\section{International Journal of Engineering Applied Sciences and Technology, 2020 Vol. 4, Issue 12, ISSN No. 2455-2143, Pages 661-666 \\ Published Online April 2020 in IJEAST (http://www.ijeast.com)}

whether it is dropped or risen, above or beyond a certain limit. It works as a safety purpose. We get feedback on actual system pressure by the pressure transducer.

D. Flow sensor:

Flow sensor is an instrument which is used to measure non-linear, linear volumetric or mass flow rate of gas or a liquid. Flow measurement is distinct area and it is essential for various engineering operations. They are classified into different types according to application, their function, area where to use etc.

E. Temperature transducers:

It is a device. By using it the thermal energy can be converted into physical quantity (pressure, displacement and electrical signal etc.). By using electric device, we can automatically measure the temperature. The temperature transducer works to measure the heat of given medium and transfer the reading (data) by converting it into readable form.

F. Switches:

Push buttons are used as switches in this project. A Pushbutton Switch is a switch designed so that its contacts are closed by pressing and opened by releasing the push button. Buttons are certainly made up of hard material, usually metal or plastic.

G. Compressor:

In this project compressor is used for two purposes, to compress air and natural gas. Compressor is a device which converts electric power into potential energy stored in pressurized air or gas.

H. Control valve:

Control valve is a valve which is used to control the flow of gas through pipeline as per instructed signal from controller. It is normally in open or closed condition as per the requirement of process. Operation of control valve i.e. opening and closing is depends on pneumatic, electric or hydraulic actuators.

\section{PROCESS FLOW DIAGRAM}

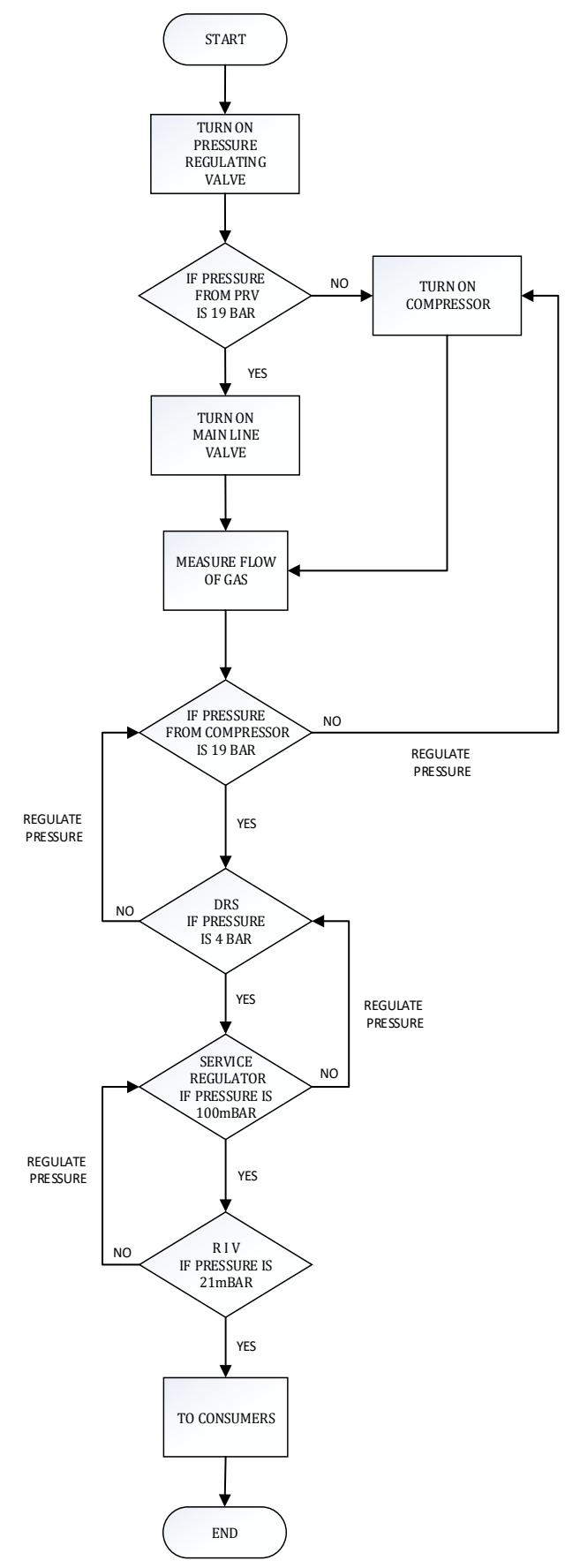

Fig.3 Process flow diagram of system

For the effective understanding of what actually happening in the Piped-Natural Gas pipeline, it is necessary to understand the flow of the whole process and this is efficiently determined by process flow diagram. 


\section{International Journal of Engineering Applied Sciences and Technology, 2020 Vol. 4, Issue 12, ISSN No. 2455-2143, Pages 661-666 \\ Published Online April 2020 in IJEAST (http://www.ijeast.com)}

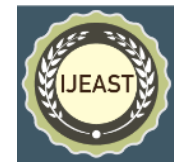

For efficient working of gas pipeline, it is necessary to maintain the constant pressure and flow of gas throughout the pipeline so as to improve overall efficiency of gas pipeline.

\section{The process flow of this project is as follows:}

A. Firstly mechanical pressure regulating valve is turned ON which brought out the gas from storage tank at constant regulated pressure.

B. Then there are two lines to transfer the gas through pipeline, first is main line and another is compressor line.

C. Main line is continuously is in operation and compressor line is standby. Compressor is required only when gas brought out from storage tank has low pressure.

D. Check reading from pressure transducer connected after main line and compressor. This pressure transducer sends command to the controller to regulate the control valve.

E. Then check readings from flow sensor and temperature sensor.

F. Now DRS is used to drop the pressure to 4 Bar according to command from controller.

G. Similarly Service regulator and RIV are used to reduce the pressure $100 \mathrm{mBar}$ and $21 \mathrm{mBar}$ respectively.

\section{I/O COUNT}

An I/O list is a document. It contains list of instrumentation. It is useful to communicate between the information processing systems.

Any program, operation or device those help to transfer data to or from a computer or to $\&$ from peripheral device, can be described by the term I/O.

Each data transfer is an output signal from one device whereas an input signal into another. Pressure Transducers $\&$ the Flow Sensors are input devices while Compressors \& Control Valves are output devices.

Basically Sensors work as input devices which offers a functional output towards a specified physical input. Sensors giving discrete or digital outputs (on/off) can be conveniently joined to the input ports of PLCs. An analog sensor gives an output which is proportional to the measured variable.

These analog signals are converted into digital signals and then they can be sent to input of PLC ports.

TOTAL I/O COUNTS - 30

\begin{tabular}{|c|c|}
\hline Input Count & Output Count \\
\hline Pressure Transducer -8 & Compressor -1 \\
\hline & \\
\hline
\end{tabular}

\begin{tabular}{|c|c|}
\hline Flow Sensor - 2 & Solenoid Valve -4 \\
\hline Temperature Sensor -1 & Control Valve -4 \\
\hline Switches -9 & Alarm -1 \\
\hline
\end{tabular}

Table no. 2

\section{PIPING AND INSTRUMENTATION DIAGRAM}

From a pipe and instrumentation diagram we get detailed schematic. The tube and process equipment along with devices and control devices and other components are demonstrated.

It provides an overview of the whole process loop of specific industry arrangements. There is an interconnection between process equipment and process control equipment in industry. It is shown by piping and instrumentation diagram (P\&ID).

This serves as a method of communication between plant operation, engineering, installation and maintenance because it provides detailed plant details on machinery, pipeline, equipment and common services, etc. The diagram provides the basis for the development of system control schemes during design phase. Further protection and organizational analysis (such as a threat and realistic study) can be accomplished.

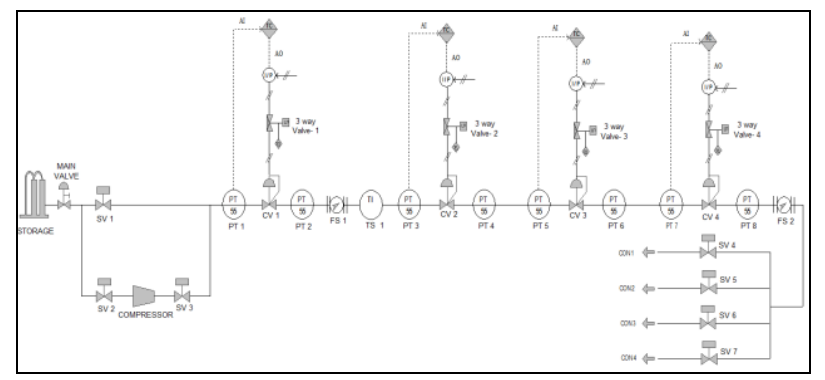

Fig.4 P\&ID

\section{RESULTS}

Simulation window:

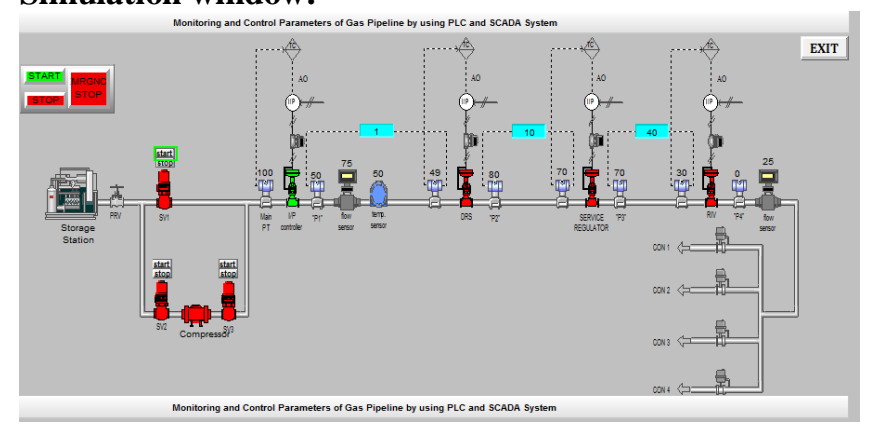


Fig.5 Simulation Window

Above simulation window exhibits a real time visualization of the Gas Pipeline which is generally observed from control room. Depending upon the operation of sensors and control equipments, indications are given by respective devices and according to that control action is taken.

This simulation widow shows different control valves and solenoid valves which are responsible to control the flow of gas through the pipeline.

Simulation window also shows different kind of sensors such as pressure transducer, flow sensor, temperature sensor. These sensors gives real time readings of gas pipeline, according to these readings control action is taken.

There are 3 displays showing pressure difference between each control valve so as to find any leakage in gas pipeline.

Control valves are operates as per command signal from PID controller. Each pressure transducer connected before control valve gives analog signal to the PID controller. Then PID regulates the control valve after opening 3 way solenoid valve. Solenoid valve operates according to PLC commands.

\section{PID control panel:}

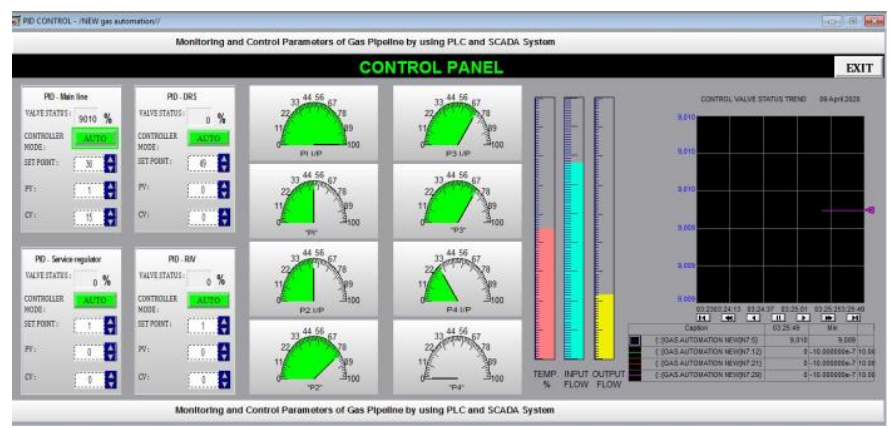

Fig.6 PID Control Panel

Above window shows PID control panel. This window contains PID controllers of all control valves, readings of pressure transducer, readings of temperature sensor and flow sensors. This window also contains graphical representation of opening and closing status of all control valves.

Each PID controller block contains different PID setup parameters such as set point (SP), process variable (PV), control output (CV), and controller mode. It also displays status of control valve.

\section{Display panel:}

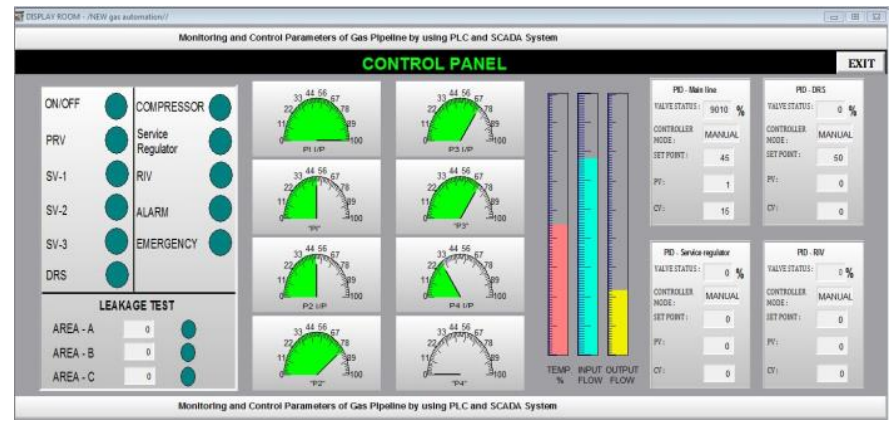

Fig.7 Display Panel

Above window shows display panel of parameters of gas pipeline and also status of leakage test.

First panel block shows indications of all the control valves, solenoid valves, ON/OFF condition, compressor status. It also shows alarm and emergency indications. controllers.

Above window also displays values of PID

\section{ADVANTAGES}

- Man power will be reduced.

- Process will be operated automatically.

- Lower operating cost.

- Leakages in pipeline will be minimize.

\section{DISADVANTAGES}

- Initial cost is high

- Person with special skills is required to handle the operation

\section{CONCLUSION}

The concept of enhanced monitoring and control using PLC and SCADA systems is covered by this project work. The detection of the leak will improve and response is rapid. If there is a leak, the process for a specific region or entire system will be automatically disconnected and also manually controlled. If the pressure drops, the buzzer will alarm.

\section{REFERENCE}

[1] P. R. P. M. R. S. K. Gosavi, "A Review on Industrial Energy Monitoring System Using PLC and SCADA," Int. Res. J. Eng. Technol., vol. 3, no. 5, pp. 1699-1701, 2016.

[2] M. A. Adegboye, W. K. Fung, and A. Karnik, "Recent advances in pipeline monitoring and oil leakage detection technologies: Principles and approaches," Sensors 
(Switzerland), vol. 19, no. 11. MDPI AG, 01-Jun-2019, doi: 10.3390/s19112548.

[3] "Overview." [Online]. Available: https://www.mahanagargas.com/business/domestic-pngoverview.aspx. [Accessed: 05-Mar-2020].

[4] "PNG Network." [Online]. Available: https://www.mahanagargas.com/business/png-network.aspx.

[Accessed: 06-Mar-2020].

[5]S.Ranjith, D.Srinath, R.Vasantha raja, G.Vignesh, \& R.Rajarajan, Chennai ,(2016, APRIL 3). "Automatic leakage detection \& control of gas pipeline using PLC," International Journal of Emerging Technology in Computer Science \& Electronics (IJETCSE), Volume 21,1-5.

[6] Savitha T.C. (2019, June 2). "PLC and SCADA based irrigation system to monitor the moisture content of agriculture fields," International Journal of Engineering Applied Sciences and Technology, Volume 4, 1-5.

[7] Pimpalkar, P. M., Gattewar, D., Bhoyar, C., Aglawe, P., \& Khobragade, P. (2020, February 10). "IOT based home automation using ATMEGA 328 Microcontroller," International Journal of Engineering Applied Sciences and Technology, Volume 4, 1-5.

[8]Chen-xi WANG, Ming-zhe LIU, Ai-dong XU, \& Ji-long ZHANG. (2017). The Application of PLC Control System in Oil and Gas Pipeline Transportation," International Conference on Mechanical Control and Automation (ICMCA 2017), 1-5.

[9] Ma Rongsuo. "The application of SCADA system in oil and gas pipeline. Digital technology and Applications,".

[10] NaturalGas.org, 2004a, "The Natural Gas Industry and the Environment." Available at http://www.naturalgas.org/environment/ng_industry_environ ment.asp. Accessed February 7, 2007.

[11] BANDA .M. K., HERTY . M., \& KLAR ,A. (2010). “Gas flow in pipeline networks,". aims' journals, $x, 1-17$.

[12] Sabu, H. M., B, A. v., Sullerey, A., \& A, B. V. (2015). "Online Monitoring of PLC Based Pressure Control System,". International Journal of Research and Innovations in Science \& Technology, 2(2), 1-4.

[13] S, R., S, K., D, S., \& R, K. (2016, Jan). "Pipeline Monitoring Using Vibroacoustic Sensing - A Review,". International Research Journal of Engineering and Technology (IRJET), 03(01), 1-5. 